\title{
One-dimensional Modelling and Optimisation of an Industrial Steam Methane Reformer
}

\author{
M. Sinaei Nobandegani, ${ }^{a, *}$ T. Darbandi, ${ }^{b}$ M. Kheirinik, \\ M. R. Sardashti Birjandi, ${ }^{d}$ F. Shahraki, ${ }^{d}$ and L. Yu \\ aChemical Technology, Luleå University of Technology, \\ SE-971 87 Luleå, Sweden \\ ${ }^{\mathrm{b}}$ Luleå University of Technology, Department of Engineering Sciences \\ and Mathematics, Energy Science, Luleå, Sweden \\ 'Persian Gulf Star Oil Company, Bandar Abbas, \\ doi: https://doi.org/10.15255/CABEQ.2021.1963 \\ Hormozgan Province, Iran \\ dDepartment of Chemical Engineering, University of Sistan \\ and Baluchestan, P.O. Box 98164-161, Zahedan, Iran \\ Original scientific paper \\ Received: April 19, 2021 \\ Accepted: September 20, 2021
}

\begin{abstract}
Steam methane reforming is one of the most promising processes to convert natural gas into valuable products such as hydrogen. In this study, a one-dimensional model was used to model and optimise an industrial steam methane reformer, using mass and thermal balances coupled with pressure drop in the reformer tube. The proposed model was validated by the experimental data. Furthermore, the effects of flowrate and temperature of the feed, tube wall temperature, and tube dimension on the reformer performance were studied. Finally, a multiobjective optimisation was done for methane slip minimisation and hydrogen production maximisation using genetic algorithm. The results illustrated the optimum feed flowrate of $2761.9 \mathrm{kmol} \mathrm{h}^{-1}$ (minimum $32 \mathrm{~mol} \%$ produced hydrogen and maximum 0.15 mol.\% unreacted methane). This is one of the few studies on investigation of steam methane reformer using a simple and effective model, and genetic algorithm.
\end{abstract}

Keywords:

hydrogen, steam reformer, optimisation, mathematical modelling, reactors

\section{Introduction}

Hydrogen energy has been proposed as a promising energy carrier over the past decades. ${ }^{1,2}$ Environmental legislation and market forces have increased the demand for hydrogen in oil refineries. Hydrocarbon reforming has been identified as the main process to produce hydrogen and other synthesis gases. ${ }^{3,4}$ The first atmospheric pressure reforming unit was established in the $1930 \mathrm{~s} .{ }^{5}$ After three decades, a steam reformer with operating capacity at 15 bar pressure came on stream in the United Kingdom. ${ }^{6}$ Due to the high ratio of hydrogen to carbon in methane, natural gas (mainly consisting of methane) is considered as a preferable feedstock in reforming to produce hydrogen. ${ }^{7}$ This ratio also minimises the amount of carbon dioxide produced as by-product. ${ }^{7}$ As already proven, ${ }^{8,9}$ steam methane reforming (SMR) is a common industrial process in hydrogen production.

Since SMR is the most commonly used technique in hydrogen production, there exist extensive industrial experience and research background in

"Corresponding author: mojtaba.nobandegani@1tu.se this area. One of the earliest studies on SMR was conducted by Fischer and Tropsch in 1928. ${ }^{10}$ They studied various catalysts in steam methane reforming at temperature range of $870-983{ }^{\circ} \mathrm{C}$, and reported that nickel and cobalt were the best catalysts for this process. So far, many catalysts have been investigated, ${ }^{11,12}$ and SMR processes have been studied extensively to improve the performance. ${ }^{13-15}$ However, SMR processes, like many industrial chemical/petrochemical processes, are complex in nature because of complicated reaction chemistry, nonlinear relations, and numerous variables involved (such as inlet steam-to-carbon ratio, wall temperature, tube geometry, flowrates and catalysts). ${ }^{16}$ Therefore, there is a great interest in modelling and optimisation of SMR reactor with a simple and reliable model. This study aimed to describe and optimise an industrial SMR using a one-dimensional model, since the ratio of diameter to the length of reformer was considerably small. ${ }^{17}$

Singh and Saraf ${ }^{18}$ simulated a side-fired hydrocarbon reformer using one-dimensional model in axial direction. Their results were in good agreement with experimental data. De Deken et al., ${ }^{3}$ by studying the SMR on a commercial catalyst at tem- 
perature range of $550-675^{\circ} \mathrm{C}$ and pressure range of 5-15 bar, suggested a kinetic mechanism for this process. They simulated the reformer based on continuity, energy, and momentum equations by one and two-dimensional models. The SMR was simulated by Alatiqi et al. ${ }^{19}$ using a rigorous kinetic model. They showed that the rigorous model could be confidently utilised for design purposes. In one of the major studies related to SMR kinetics, $\mathrm{Xu}$ and Froment ${ }^{20}$ successfully derived an intrinsic rate equation for the SMR on $\mathrm{Ni} / \mathrm{MgAl}_{2} \mathrm{O}_{3}$ catalyst. Alhabdan et al $^{21}$ developed a heterogeneous model for industrial steam reformers and compared the results with a number of side-fired and top-fired industrial reformers. Using a numerical method, Nummedal et al. ${ }^{22}$ minimised the total entropy production rate. This optimal path reduced the entropy production by more than $60 \%$ in comparison with the typical path. Riaz et al. ${ }^{23}$ investigated the inert gas on SMR using a heterogeneous model. They reported that using xenon as the inert gas can reduce the outlet temperature $20 \%$ compared to traditional mode. Pantoleontos et al. ${ }^{24}$ examined the dynamic behaviour of industrial heterogeneous steam reforming of methane. Using a set of partial differential equations, their model was capable of describing physicochemical processes, which occur in solid and gas phase considering the diffusional limitations in catalyst particles. They validated the computed results through the literature-reported data. They also optimised the provided heat for the reactor wall in terms of the optimal hydrogen production. The synthesis gas production by SMR was simulated by a pseudo-heterogeneous model by Sadooghi and Rauch. ${ }^{25}$ The results proved that the radial concentration gradient was insignificant in the reformer. Shinde and Modras ${ }^{26}$ reported a sonochemical-assisted synthesis of a highly active and coke resistant $\mathrm{Ni} / \mathrm{TiO}_{2}$ catalyst for SMR. The results showed that the synthesised catalyst was remarkably active and stable even after a long period, and no appreciable coke deposition was observed. Industrial reformer performance has been modelled by our group in another study, ${ }^{15}$ where the response surface methodology was used to optimise the reformer performance, and the optimum values were reported.

In the present work, the same industrial SMR unit and the process were modelled using the genetic algorithm, within different operating constraints, and optimum values to maximise the hydrogen production and minimise the unreacted methane, simultaneously. The aim of this study was associated with describing SMR using a one-dimensional mathematical model in an axial direction in steadystate conditions to investigate the effect of operating parameters on methane conversion. To the best of our knowledge, this is the first attempt to model and optimise the industrial side-fired steam methane reformer located in Bandar Abbas refinery, using a simple and reliable model and genetic algorithm. Genetic algorithm was chosen since it is one of the popular metaheuristics optimisation techniques with a strong capability in global optimisation. ${ }^{27}$ The results would be helpful in optimisation of SMR performance in this refinery, as well as in designing other SMR reactors.

\section{Process description}

Although both endothermic and exothermic reactions occur over catalyst, SMR is considered generally as a highly endothermic process. Therefore, to provide the required heat, it can be performed in a set of catalytic tubes located inside a furnace with some burners (224 burners in Bandar Abbas reformer). ${ }^{28-30}$ The SMR occurs in a tubular reactor at 800 $1000{ }^{\circ} \mathrm{C}$ and 5-35 bar. Although some metal-based catalysts such as rhodium, ruthenium, platinum, and palladium can be used in SMR process, nickel is the most common one, since it is not as expensive as other candidates. ${ }^{30,11}$ The steam reforming of methane is a complex process, in which several reactions may occur at the same time, as described by Xu and Froment. ${ }^{20}$ However, it can be described by three main chemical reactions that are endothermic in overall: ${ }^{20,24}$

$$
\begin{gathered}
\mathrm{CH}_{4}+\mathrm{H}_{2} \mathrm{O} \rightleftarrows \mathrm{CO}+3 \mathrm{H}_{2} \\
\Delta \quad=-2.061 \cdot 10^{5} \mathrm{~kJ} \mathrm{kmol}^{1} \\
\mathrm{CO}+\mathrm{H}_{2} \mathrm{O} \rightleftarrows \mathrm{CO}_{2}+\mathrm{H}_{2} \\
\Delta H_{r}=+4.11 \cdot 10^{4} \mathrm{~kJ} \mathrm{kmol}^{-1} \\
\mathrm{CH}_{4}+2 \mathrm{H}_{2} \mathrm{O} \rightleftarrows \mathrm{CO}_{2}+4 \mathrm{H}_{2} \\
\Delta H_{r}=-1.65 \cdot 10^{5} \mathrm{~kJ} \mathrm{kmol}^{-1}
\end{gathered}
$$

Because of the endothermicity and mole increased reaction processes, high temperatures and low pressures are desired operating conditions for reactions (1) and (3). Water-gas shift (WGS) reaction (2), which is temperately exothermic, is needed when hydrogen is the desired product. Due to being an exothermal reaction, the WGS benefits from low temperatures. Therefore, for the SMR process, a high-temperature shift convertor (HTSC) followed by a low-temperature shift convertor (LTSC) is profitable. ${ }^{31,32}$

\section{Method}

\section{Mathematical modelling}

Fig. 1 indicates a simple schematic of a reformer tube. Similar to other modelling studies, our assumptions were as follows: 


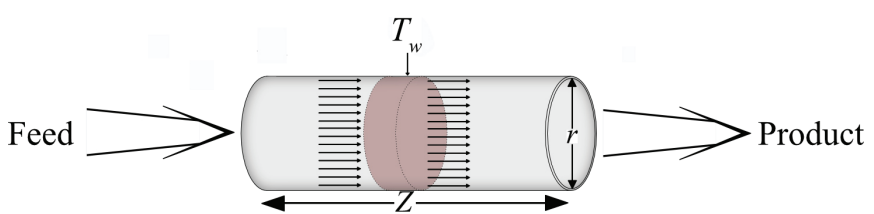

Fig. 1 - Reformer tube schematic

a) The tube is modelled in axial direction, because the ratio of diameter to the length of reformer is considerably small ${ }^{19}$ (inner diameter of $0.098 \mathrm{~m}$ and heated length of $13.6 \mathrm{~m}$, which corresponds to $D / L \approx 0.007)$, and the reactions are endothermic in overall. ${ }^{24}$

b) The process gas passes through the catalyst tube, following a plug flow pattern. c) For better thermal performance, the SMR works as a set of catalytic tubes located inside a furnace with 224 burners. These tubes have the feed in the same conditions, with an equal input flowrate, pressure, and temperature. Moreover, the boundary conditions for all tubes at $z=0$ are the same, and the conversion is equal to zero at this point. Using the assumption that the heat flux passing through each tube wall is identical, all the tubes (regardless of their positions) have the same patterns. Consequently, it is assumed that each tube is representative of any other in furnace, and the model is derived for one tube instead of 328 tubes. d) All the heavier hydrocarbons hydrocrack and convert to methane before entering the tube. e) The ratio of diameter to the length of reformer is too small and the Peclet number is too
Table 1 -Characteristics of steam methane reformer in Bandar Abbas refinery, Iran

\begin{tabular}{lc}
\hline \multicolumn{2}{c}{ Tube characteristics } \\
\hline Number of tubes & 328 \\
Number of burners & 224 \\
Tube inner diameter (m) & 0.098 \\
Tube outer diameter (m) & 0.111 \\
Heated tube length (m) & 13.6 \\
Type & Catalyst characteristics \\
\hline & $\mathrm{Ni} / \mathrm{MgO} \mathrm{Al}_{2} \mathrm{O}_{3}$ \\
\hline Catalyst & $\mathrm{Ring} \mathrm{shape}$ \\
Shape & $\mathrm{L}(17) \times \mathrm{ID}(6) \times \mathrm{OD}(17)$ \\
Dimension (mm) & 2355.5 \\
Catalyst density $\left(\mathrm{kg} \mathrm{m}^{-3}\right)$ & 29520 \\
Mass of catalyst $\left(\mathrm{kg}^{2}\right.$ & 1051 \\
Catalyst bed density $\left(\mathrm{kg} \mathrm{m}^{-3}\right)$ & 0.605 \\
Catalyst bed void fraction
\end{tabular}

high, as a result, the axial dispersion is neglected. $\mathrm{f}$ ) Catalysts particle temperature and shape are uniform. g) Van der Waals equation of state is applied in gas density calculation. Characteristics of the reformer are presented in Table 1.

Considering the mentioned assumptions, the final model can be expressed as the following governing equations: ${ }^{20}$

$$
\begin{gathered}
\frac{\mathrm{d} x_{\mathrm{CH}_{4}}}{\mathrm{~d} z}=\frac{\rho_{b} \cdot M w_{m}}{y_{\mathrm{CH}_{4}}^{0} \cdot \rho_{g} \cdot u_{g}} \cdot\left(r_{1} \eta_{1}+r_{3} \eta_{3}\right) \quad z=0 \longrightarrow x_{\mathrm{CH}_{4}}=0 \\
\frac{\mathrm{d} x_{\mathrm{CO}_{2}}}{\mathrm{~d} z}=\frac{\rho_{b} \cdot M w_{m}}{y_{\mathrm{CO}_{2}}^{0} \cdot \rho_{g} \cdot u_{g}} \cdot\left(r_{2} \eta_{2}+r_{3} \eta_{3}\right) \quad z=0 \longrightarrow x_{\mathrm{CO}_{2}}=0 \\
\frac{\mathrm{d} T}{\mathrm{~d} z}=\frac{1}{G \cdot C_{p_{m}}} \cdot\left(\frac{4 \cdot U \cdot\left(T_{w}-T\right)}{d_{i}}+\rho_{b} \cdot \sum_{i=1}^{3}\left(-\Delta H_{i}\right) \cdot \eta_{i} \cdot r_{i}\right) \quad z=0 \longrightarrow T=T_{i n} \\
\frac{\mathrm{d} p}{\mathrm{~d} z}=-\left(150 \cdot \frac{\left(1-\varepsilon_{b}\right)^{2}}{\varepsilon_{b}^{3}} \cdot \frac{\mu \cdot u_{g}}{D_{p}^{2}}+1.75 \cdot \frac{\left(1-\varepsilon_{b}\right)^{2}}{\varepsilon_{b}^{3}} \cdot \frac{G \cdot u_{g}}{G_{p}}\right) z=0 \longrightarrow p=p_{i n}
\end{gathered}
$$

Since the catalyst in Bandar Abbas steam reformer is $\mathrm{Ni} / \mathrm{MgO} \mathrm{Al} \mathrm{O}_{3}$, the reaction rates given by $\mathrm{Xu}$ and Froment were used in the kinetic model based on the Langmuir-Hinshelwood reaction mechanism: ${ }^{20}$

$$
\begin{aligned}
& r_{1}=\frac{k_{1}}{p_{\mathrm{H}_{2}}^{2.5} \cdot D E N^{2}} \cdot\left(p_{\mathrm{CH}_{4}} \cdot p_{\mathrm{H}_{2} \mathrm{O}}-\frac{p_{\mathrm{H}_{2}}^{3} \cdot p_{\mathrm{CO}}}{K_{e q_{1}}}\right) \\
& r_{2}=\frac{k_{2}}{p_{\mathrm{H}_{2}} \cdot D E N^{2}} \cdot\left(p_{\mathrm{CO}} \cdot p_{\mathrm{H}_{2} \mathrm{O}}-\frac{p_{\mathrm{H}_{2}} \cdot p_{\mathrm{CO}_{2}}}{K_{e q_{2}}}\right) \\
& r_{3}=\frac{k_{3}}{p_{\mathrm{H}_{2}}^{3.5} \cdot D E N^{2}} \cdot\left(p_{\mathrm{CH}_{4}} \cdot p_{\mathrm{H}_{2} \mathrm{O}}^{2}-\frac{p_{\mathrm{H}_{2}}^{4} \cdot p_{\mathrm{CO}_{2}}}{K_{e q_{3}}}\right)
\end{aligned}
$$


In equations (8-10), $D E N$ is defined as follows:

$$
D E N=1+K_{\mathrm{CH}_{4}} \cdot p_{\mathrm{CH}_{4}}+K_{\mathrm{CO}} \cdot p_{\mathrm{CO}}+K_{\mathrm{H}_{2}} \cdot p_{\mathrm{H}_{2}}^{0.5}+K_{\mathrm{H}_{2} \mathrm{O}} \cdot\left(\frac{p_{\mathrm{H}_{2} \mathrm{O}}}{p_{\mathrm{H}_{2}}}\right)
$$

The kinetic rate coefficients and adsorption equilibrium constants are given as: ${ }^{33}$

$$
\begin{gathered}
k_{1}=2.64 \cdot 10^{14.5} \exp \left(-\frac{28879}{T}\right) \\
k_{2}=1.22 \cdot 10^{-2} \exp \left(-\frac{8074.3}{T}\right) \\
k_{3}=6.63 \cdot 10^{13.5} \exp \left(-\frac{29336}{T}\right) \\
K_{\mathrm{CH}_{4}}=6.65 \cdot 10^{-9} \exp \left(\frac{4604.28}{T}\right) \\
K_{\mathrm{H}_{2} \mathrm{O}}=1.77 \cdot 10^{5} \exp \left(-\frac{10666.35}{T}\right) \\
K_{\mathrm{CO}}=8.23 \cdot 10^{-10} \exp \left(\frac{8497.71}{T}\right) \\
K_{\mathrm{H}_{2}}=6.12 \cdot 10^{-14} \exp \left(\frac{9971.13}{T}\right) \\
K_{e q_{1}} 10266.76 \cdot 10^{6} \exp \left(-\frac{26830}{T}+30.114\right) \\
K_{e q_{2}}=\exp \left(\frac{4400}{T}+4.036\right) \\
K_{e q_{3}}=K_{e q_{1}} \cdot K_{e q_{2}}
\end{gathered}
$$

The effectiveness factor has been reported by AL-Dhfeery and Jassem: ${ }^{34}$

$$
\eta_{k}=\frac{1}{\varphi_{k}}\left[\left(\frac{1}{\tanh \left(3 \varphi_{k}\right)}\right)-\left(\frac{1}{3 \varphi_{k}}\right)\right]
$$

The effectiveness factor is there to correct the reaction rate, since the molecular diffusion into the catalyst pores can affect the actual reaction rate. In equation $22, \varphi_{\mathrm{k}}$ is the Thiele modulus that shows the relation between the catalytic activity and particle size. In cylindrical particles, Thiele modulus can be defined as: ${ }^{35}$

$$
\phi_{j}=\frac{r_{0}}{2} \cdot \sqrt{\frac{k_{v_{j}}}{D_{e j}}}
$$

where $k_{v_{j}}$ shows the reaction rate constant for a volume unit of catalyst. In equation $23, D_{e, j}$ represents the effective diffusivity of $i$-th component into the bulk phase: ${ }^{36}$

$$
\frac{1}{D_{e, j}}=\frac{1}{D_{i, K}}+\frac{1}{D_{i, m i x}}
$$

in which, $j$ shows the reaction number, and $i$ stands for the component. In this equation, $D_{i, k}$ shows the Knudsen diffusivity and is calculated as ${ }^{36}$

$$
D_{i, k}=\frac{4}{3} \cdot r \cdot\left\{\frac{2 \cdot R \cdot T}{\pi \cdot M_{i}}\right\}
$$

In equation $24, D_{i, m i x}$ shows the diffusion of $i$ into the mixture and is calculated as: ${ }^{36,37}$

$$
\begin{gathered}
D_{i, m i x}=\frac{\left(1-x_{i}\right)}{\sum_{\substack{j=1 \\
j \neq i}}^{n} \frac{x_{j}}{D_{e_{i, j}}}} \\
D_{e_{i, j}}=\frac{0.36 \cdot 0.001858 T^{3 / 2} \cdot\left(\frac{1}{M_{i}}+\frac{1}{M_{j}}\right)^{1 / 2}}{p \cdot \sigma_{i, j}^{2} \cdot \Omega_{i, j}} \\
\Omega_{i, j}=\frac{1.06036}{T_{i, j}^{*} 0.1561}+\frac{0.193}{\exp \left(0.47635 \cdot T_{i, j}^{*}\right)}+ \\
\frac{1.03587}{\exp \left(1.52996 \cdot T_{i, j}^{*}\right)}+\frac{1.76474}{\exp \left(3.89411 \cdot T_{i, j}^{*}\right)} \\
T_{i, j}^{*}=\frac{T}{\left(\frac{\varepsilon}{k}\right)_{i, j}} \\
=\left(\left(\frac{\varepsilon}{k}\right)_{i} \cdot\left(\frac{\varepsilon}{k}\right)_{j}\right)^{1 / 2} \\
\sigma_{i, j}=\frac{\left(\sigma_{i}+\sigma_{j}\right)}{2}
\end{gathered}
$$

where $x$ shows the mole fractions, $p$ is pressure, $T$ is temperature, and $M$ is the molecular weight. $\sigma$ and $\left(\frac{\varepsilon}{k}\right)_{i}$ are Lennard-Jones parameters, and are expressed as: $:^{37}$

$$
\begin{gathered}
\sigma_{i}=0.84 \cdot v_{c_{i}}^{1 / 3} \\
\left(\frac{\varepsilon}{k}\right)_{i}=0.77 \cdot T_{c_{i}}
\end{gathered}
$$

in which $v_{c}$ and $T_{c}$ are the critical volume and temperature of $i$ component.

The gas density was computed based on the assumption that the Van der Waals equation of state can be used. In equation (6), the overall heat coefficient and enthalpy variations are calculated by equations (34-35), respectively: ${ }^{38,39}$ 


$$
\begin{gathered}
U=0.4 \cdot \frac{K_{g}}{D_{p}} \cdot\left\{2.58 \cdot\left(\frac{D_{p} \cdot G}{\mu}\right)^{\frac{1}{3}} \cdot\left(\frac{C_{p} \cdot \mu}{K_{g}}\right)^{\frac{1}{3}}+0.094 \cdot\left(\frac{D_{p} \cdot G}{\mu}\right)^{0.8} \cdot\left(\frac{C_{p} \cdot \mu}{K_{g}}\right)^{0.4}\right\} \\
\Delta H_{r}=\Delta H_{r}^{298}+\nabla A \cdot\left(T_{2}-T_{1}\right)+\frac{\nabla B}{2} \cdot\left(T_{2}^{2}-T_{1}^{2}\right)+\frac{\nabla C}{3} \cdot\left(T_{2}^{3}-T_{1}^{3}\right)+\frac{\nabla D}{2} \cdot\left(T_{2}^{4}-T_{1}^{4}\right)
\end{gathered}
$$

$C_{p}$ is the specific heat and can be calculated using the following equation: ${ }^{40}$

$$
C_{p}=A+B T+C T^{2}+D T^{3}
$$

$A, B, C$, and $D$ in equations (35-36) are constants and have been reported in Table 2 .

Viscosity was calculated as reported by Chung et al. ${ }^{41}$ To solve the model, there are different numerical techniques. The second order Rosenbrock method was utilised to solve the introduced model, which is a useful method in solving stiff differential equation. The catalysts pellet equivalent diameter was equal to $0.0109 \mathrm{~m}$ (more information about the catalyst properties can be found in Table 1). Moreover, the carbon dioxide to methane, steam to methane, and hydrogen to methane molar ratios in the feed were $0.004,7.630$, and 0.005 , respectively. The other input data of model are reported in Table 3.

\section{Optimisation}

The genetic algorithm and Matlab software were employed to optimise the process. During the optimisation, the hydrogen production maximisation and the methane loss (methane slip) minimisation were studied as the objective functions. The optimisation formulation is reported in equation (37).

Minimise: $f_{1}(x)=y_{\mathrm{CH}_{4}}$ and

Maximise: $f_{2}(x)=y_{\mathrm{H}_{2}}$
It was shown by Srinivas and $\mathrm{Deb}^{42}$ that, instead of the maximisation of a function like $G$, it is possible to minimise a function like $I, I=1 / G$. Consequently, the final format of the problem can be written as follow:

Minimise: $f_{1}(x)=y_{\mathrm{CH}_{4}}$ and

Minimise: $f_{2}(x)=\frac{1}{y_{\mathrm{H}_{2}}}$

Subject to:

$$
T_{w} \leq 1200 \mathrm{~K}
$$

$$
F_{i n} \leq 9000 \mathrm{kmol} \mathrm{h}^{-1}
$$

In this optimisation, the decision variables bounds are described as follows:

$$
\begin{gathered}
0 \leq\left(\frac{H}{C}\right)_{\text {in }} \leq 0.5 \\
2 \leq\left(\frac{S}{C}\right)_{\text {in }} \leq 8 \\
650 \leq T_{\text {in }} \leq 815 \mathrm{~K} \\
23 \leq p_{\text {in }} \leq 27 \text { bar }
\end{gathered}
$$

The lower and upper limits in equation (39) are selected to keep catalysts active at the entrance of the tube and to avoid excess recycling of hydrogen, respectively. In equation (40), the minimum steam to methane ratio was set at 2 , which enables neglecting the coke (carbon) formation and deposition

Table 2 -Molar heat constants ${ }^{41}$

\begin{tabular}{l|c|c|c|c}
\hline \multicolumn{1}{c|}{ Material } & $\begin{array}{c}\mathrm{A} \\
\left(\mathrm{J} \mathrm{mol}^{-1} \mathrm{~K}^{-1}\right)\end{array}$ & $\begin{array}{c}\mathrm{B} \\
\left(\mathrm{J} \mathrm{mol}^{-1} \mathrm{~K}^{-2}\right)\end{array}$ & $\begin{array}{c}\mathrm{C} \\
\left(\mathrm{J} \mathrm{mol}^{-1} \mathrm{~K}^{-3}\right)\end{array}$ & $\begin{array}{c}\mathrm{D} \\
\left(\mathrm{J} \mathrm{mol}^{-1} \mathrm{~K}^{-4}\right)\end{array}$ \\
\hline Methane & 19.89 & $5.02 \cdot 10^{-2}$ & $1.27 \cdot 10^{-5}$ & $-1.10 \cdot 10^{-8}$ \\
Steam & 32.24 & $1.92 \cdot 10^{-3}$ & $1.06 \cdot 10^{-5}$ & $3.51 \cdot 10^{-9}$ \\
Carbon monoxide & 28.16 & $1.68 \cdot 10^{-3}$ & $5.37 \cdot 10^{-6}$ & $-2.22 \cdot 10^{-9}$ \\
Carbon dioxide & 22.26 & $5.98 \cdot 10^{-2}$ & $-3.50 \cdot 10^{-5}$ & $7.47 \cdot 10^{-9}$ \\
Hydrogen & 29.11 & $-1.92 \cdot 10^{-3}$ & $4.00 \cdot 10^{-6}$ & $-8.70 \cdot 10^{-10}$ \\
Nitrogen & 28.90 & $-1.57 \cdot 10^{-3}$ & $8.08 \cdot 10^{-6}$ & $-2.87 \cdot 10^{-9}$ \\
\hline
\end{tabular}

Table 3-Model input data

\begin{tabular}{c|c|c|c|c|c}
\hline Parameter & Reactor length & Tube diameter & Catalyst density & Bed density & Bed porosity \\
\hline Value & $13.6 \mathrm{~m}$ & $0.098 \mathrm{~m}$ & $2355.2 \mathrm{~kg} \mathrm{~m}^{-3}$ & $1051 \mathrm{~kg} \mathrm{~m}^{-3}$ & 0.605 \\
\hline
\end{tabular}


on catalysts surface. ${ }^{6,25,43}$ The maximum value was selected to prohibit the adverse effects on process economics. The lower boundary of input feed temperature was set at $650 \mathrm{~K}$ based on thermodynamic limitation (in order to avoid gum formation on catalyst particles), and the upper was set at $815 \mathrm{~K}$ based on maximum practical value in the refinery. For the input feed pressure, the minimum and maximum values were selected based on the hydrogen production pressure in the refinery and the feed supply pressure.

\section{Results and discussion}

The output data predicted by the model were compared and validated with the industrial data, which were reported by Bandar Abbas industrial oil refining complex, Iran, to evaluate the accuracy of the model. The results are reported in Table 4, and the model predictions of methane conversion, temperature distribution profiles, and pressure drop are illustrated in Fig. 2. To determine the error in Table 4 , equation 43 was used:

$$
\text { Error }(\%)=\frac{\mid \text { Experimental-Calculated }}{\text { Experimental }_{\text {value }}} \cdot 100
$$

The average error for the model predictions equalled approximately $3.77 \%$.

After validating model accuracy, the effects of feed temperature and flowrate, as well as tube wall temperature on the reformer performance were investigated. As may be seen in Fig. 3, the higher wall temperature resulted in higher methane conversion. Indeed, higher wall temperature increased the temperature difference, which is the driving force for the heat transfer to the reaction. Considering reactions 1 and 3, it was observed that the reactions moved forward at higher temperature, and more methane was consumed at higher temperature.

Fig. 4a illustrates that the feed temperature had the same effect as the wall temperature. Because of the endothermic nature of the SMR process, increased temperature caused reactions (1) and (3) to shift more to the right and more methane to be converted. Therefore, higher feed temperature led to an increase in methane conversion and, therefore, re-

Table 4-Comparison between model results and experimental results

\begin{tabular}{ccc|c}
\hline Parameter & $\begin{array}{c}\text { Model } \\
\text { results }\end{array}$ & $\begin{array}{c}\text { Experimental } \\
\text { data }\end{array}$ & $\begin{array}{c}\text { Error } \\
(\%)\end{array}$ \\
\hline Methane conversion $(\%)$ & 76.00 & 75.30 & 0.96 \\
Output temperature $\left({ }^{\circ} \mathrm{C}\right)$ & 704.80 & 730.00 & 3.45 \\
Pressure drop (bar) & 0.54 & 0.58 & 6.90 \\
\hline
\end{tabular}

duced methane loss. The results are consistent with the reported results of thermodynamic analysis. ${ }^{44}$

The effect of the feed flowrate on the process is shown in Fig. 4b. Methane conversion decreased with the increase in feed flowrate. The higher feed
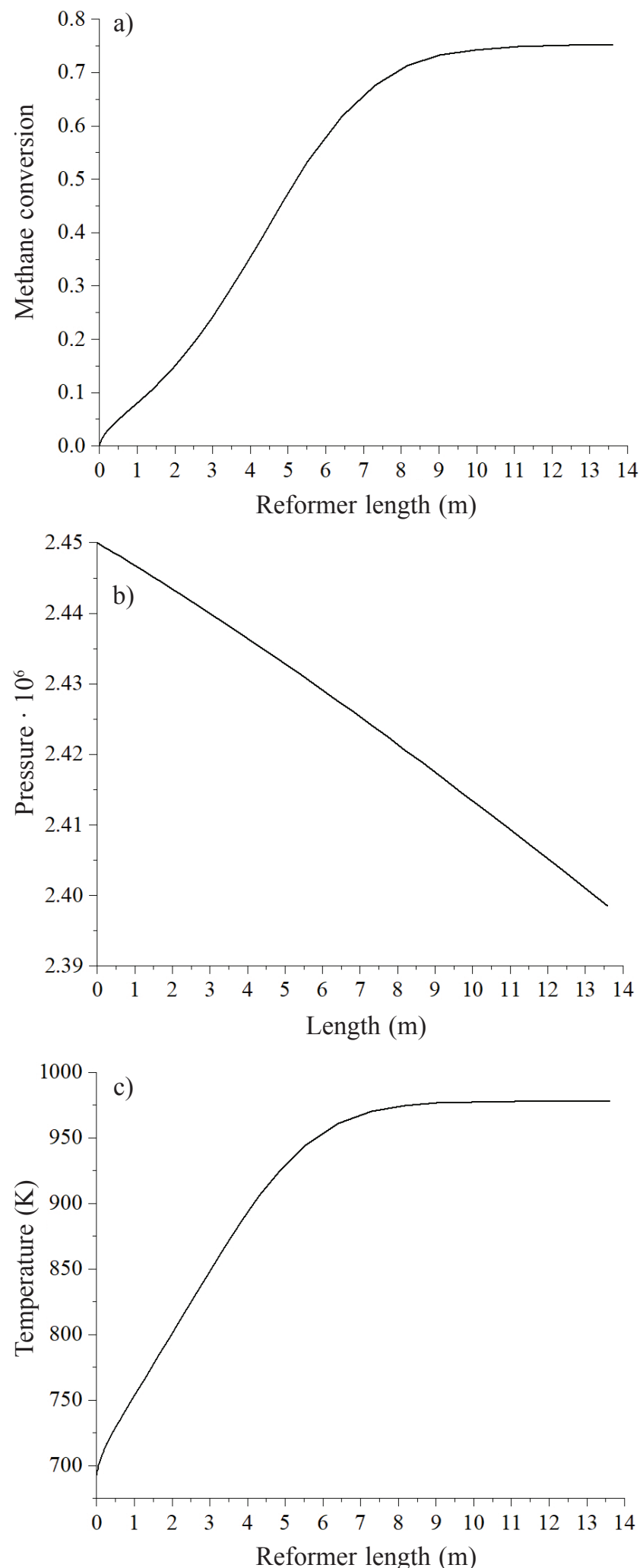

Fig. 2 - Methane conversion; b) pressure drop; c) temperature profile in reformer 


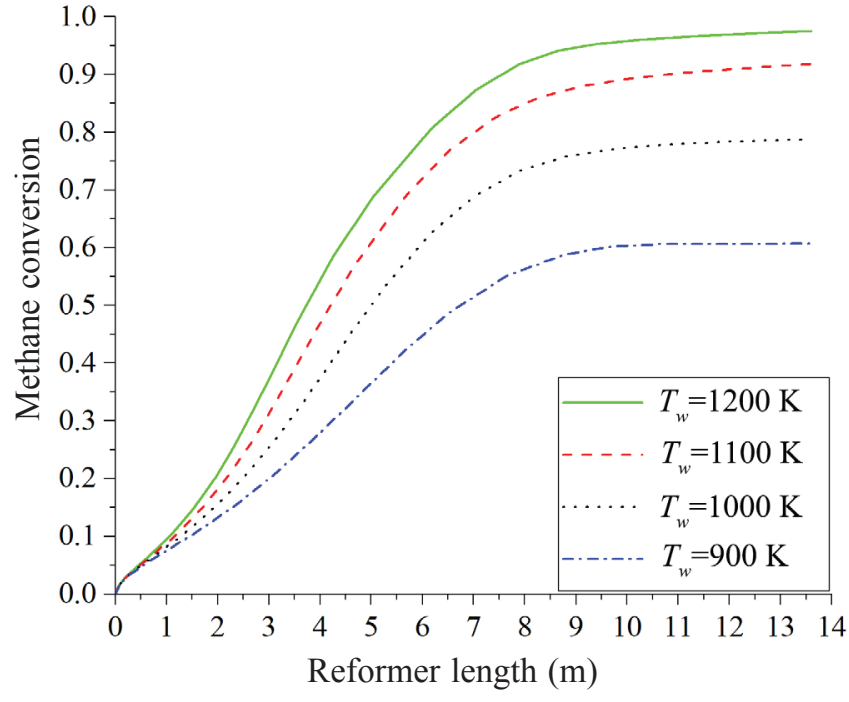

Fig. 3 - Tube wall temperature effect on methane conversion
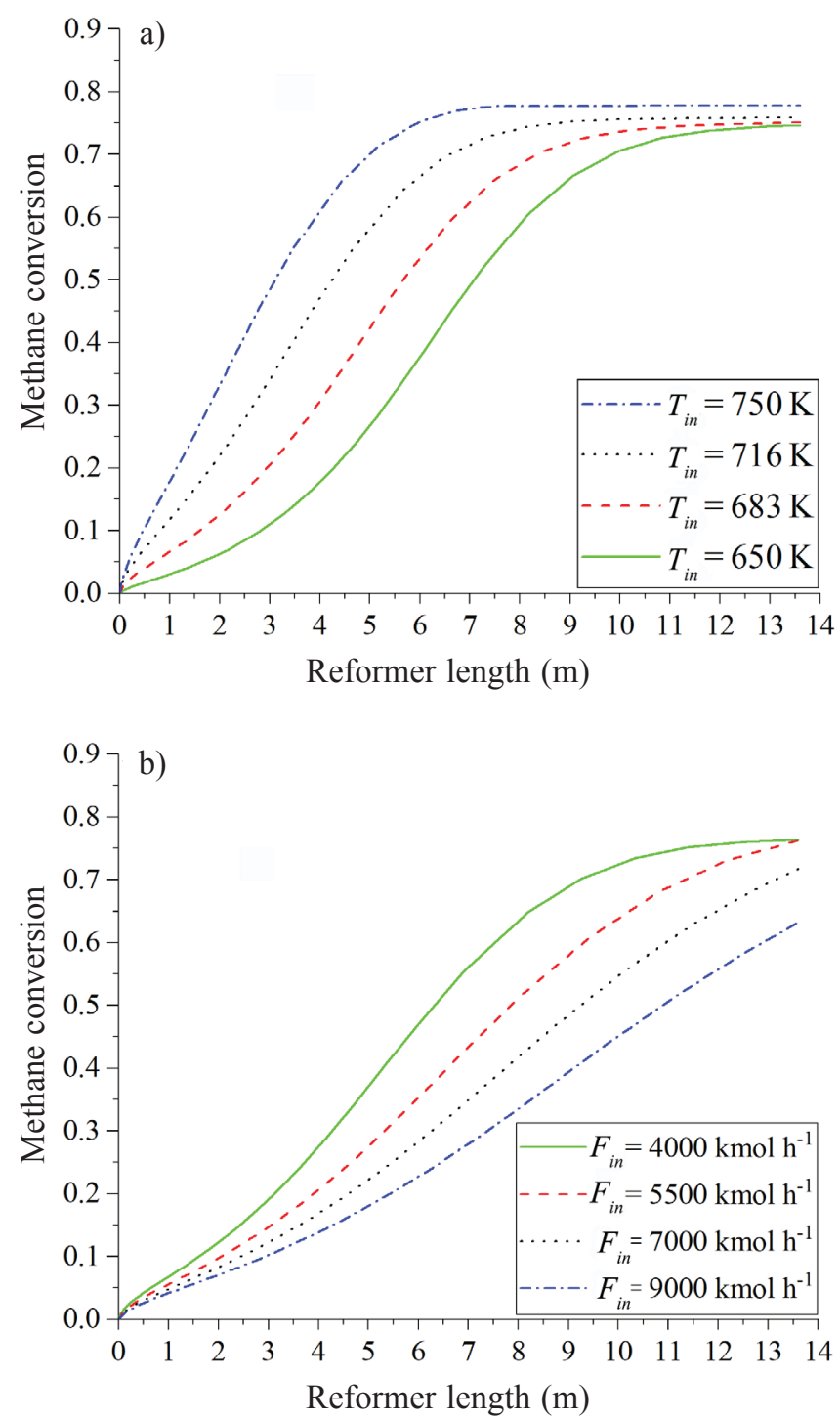

Fig. 4 - Effects of feed temperature (a), and flowrate (b) on methane conversion

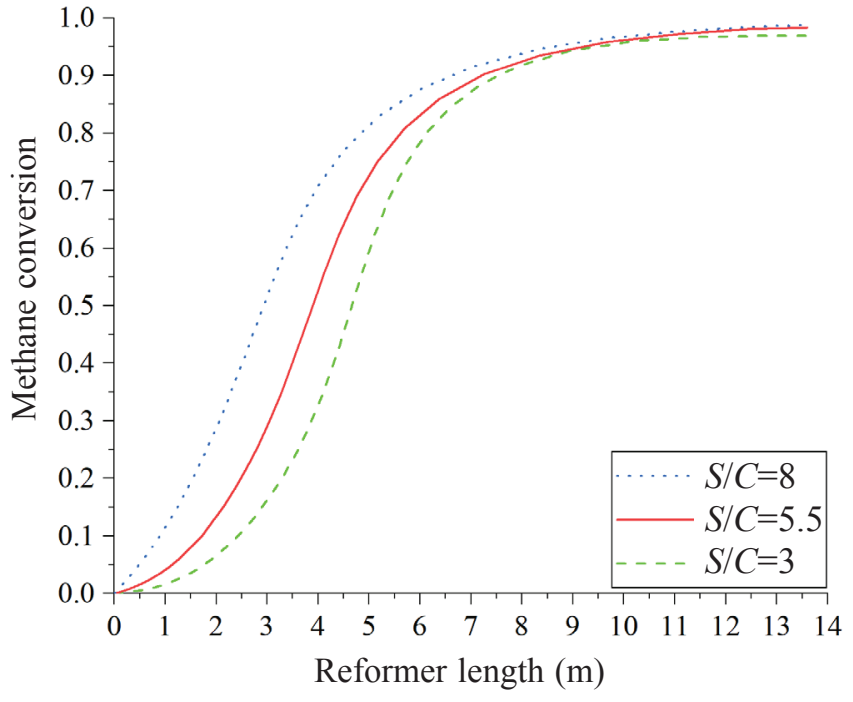

Fig. 5 - Effect of $\left(\frac{S}{C}\right)_{\text {in }}$ on methane conversion

flowrate decreased the residence time of the feed, and caused lower heat transfer. As a result, the reacted methane as well as the methane conversion decreased at higher feed flowrates.

The effect of steam to methane ratio $\left(\frac{S}{C}\right)_{\text {in }}$ in the feed flow was examined by varying its value from 3 to 8, and results are illustrated in Fig. 5. As may be seen, increasing the $\left(\frac{S}{C}\right)_{\text {in }}$ ratio increased the methane conversion, which is consistent with other reports. ${ }^{43-46}$ Indeed, increasing $\left(\frac{S}{C}\right)_{\text {in }}$ ratio will decrease the carbon deposition by increasing the gasification rate of surface carbon: ${ }^{43,47}$

$$
\mathrm{C}_{\text {surface }}+\mathrm{H}_{2} \rightarrow \mathrm{CO}+\mathrm{H}_{2}
$$

Moreover, based on Le Chatelier's principle and considering equations (1) and (3), more steam in feed stream would shift these reactions to the right, which in turn, leads to higher methane conversion as well as higher hydrogen production. ${ }^{48}$

Fig. 6 shows the temperature and methane conversion profiles at different reformer lengths and diameters. As may be observed, using longer reformer tube leads to higher methane conversion as well as higher temperature of output gas. The same effect may be seen for reformer tube diameter. However, it should be noted that the effect of increasing reformer length and diameter on methane conversion and temperature is moderated at higher values. Indeed, it may be seen that a reformer with a length of 9 to $10 \mathrm{~m}$ would be sufficient to achieve the final value of methane conversion. 
a)

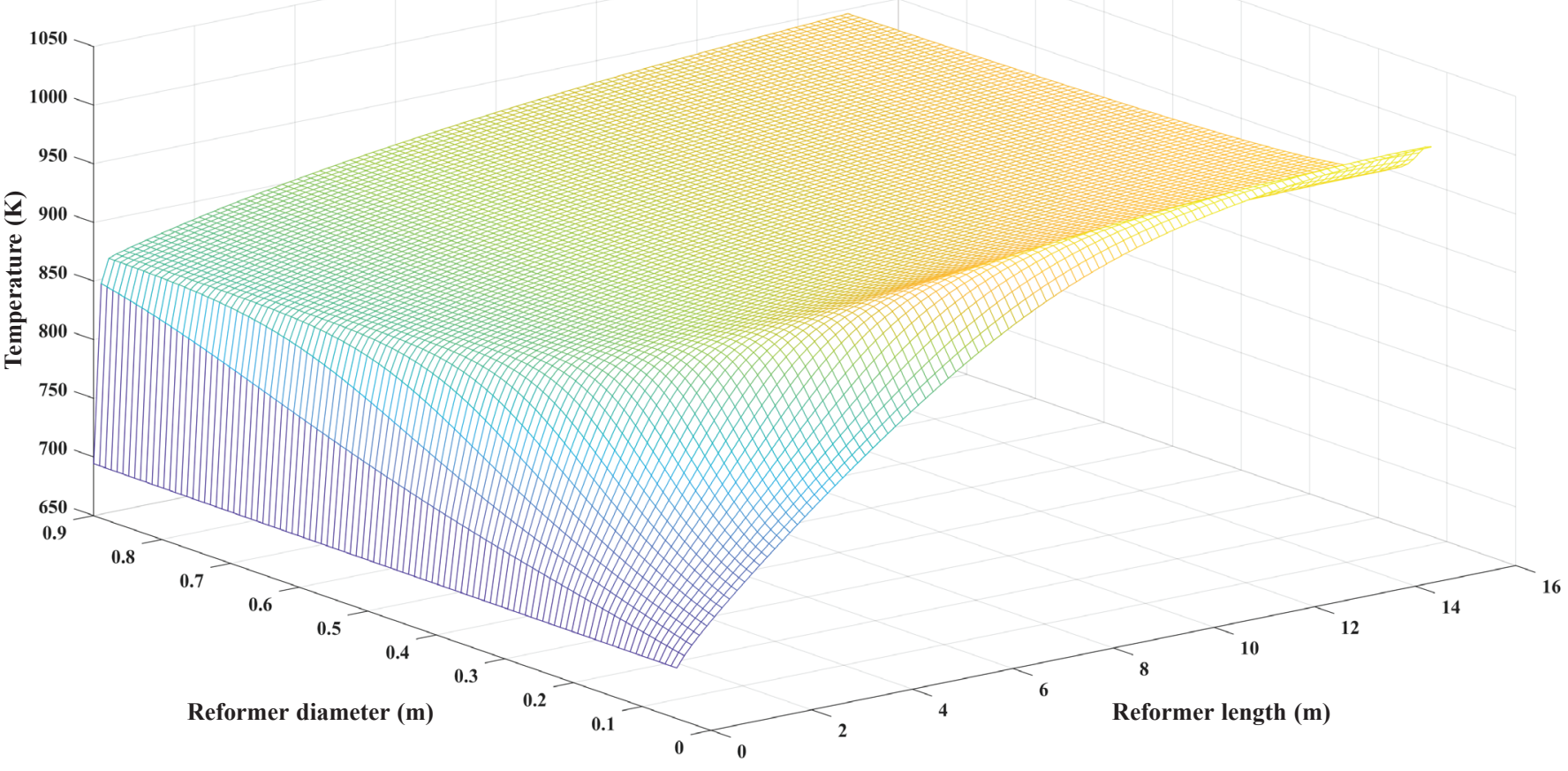

b)

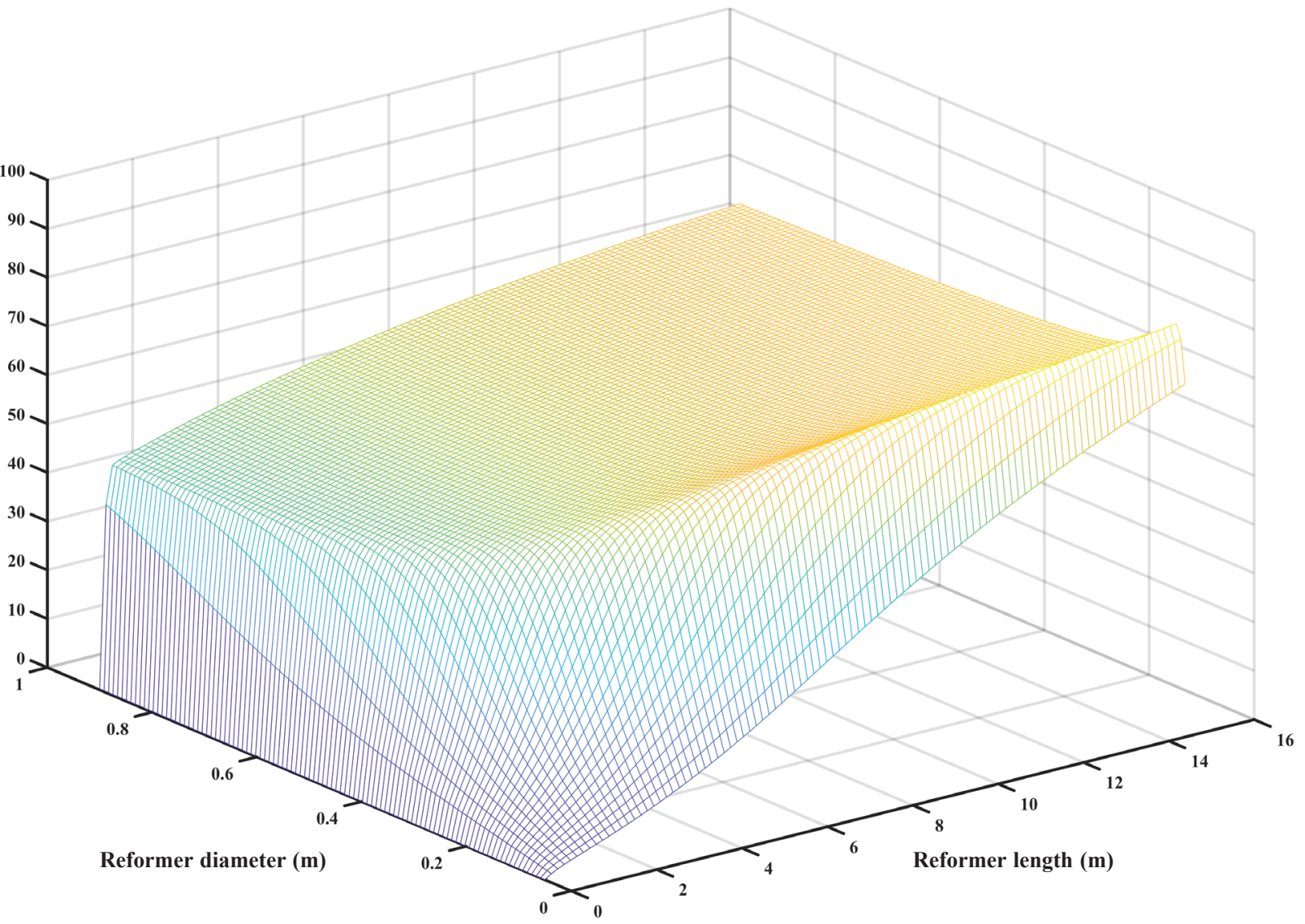

Fig. 6 - Effect of reformer dimension on: a) temperature, b) methane conversion 
Table 5-Optimum values for decision variables

\begin{tabular}{lcc|c}
\hline \multicolumn{1}{c|}{ Variable } & $\begin{array}{c}\text { Optimum } \\
\text { value }\end{array}$ & Variable & $\begin{array}{c}\text { Optimum } \\
\text { value }\end{array}$ \\
\hline Feed temperature $(\mathrm{K})$ & 768.6 & $(S / C)_{\text {in }}$ & 7.999 \\
Feed pressure (bar) & 24.4 & $(H / C)_{i n}$ & 0.005 \\
Feed flowrate $\left(\mathrm{kmol} \mathrm{h}^{-1}\right)$ & 2761.9 & $T_{w}$ & 1195.8 \\
\hline
\end{tabular}

The optimised results are reported in Table 5. For the feed flow of $2761.9 \mathrm{kmol} \mathrm{h}^{-1}$, the maximum flow of hydrogen production, and the minimum value for the unreacted methane will be $885.2 \mathrm{kmol} \mathrm{h}^{-1}$ and $4.1 \mathrm{kmol} \mathrm{h}^{-1}$, respectively.

\section{Conclusion}

In this work, the steam methane reformer was studied. This process was numerically investigated using a one-dimensional model in length direction in steady state condition. The obtained results were comparatively validated against the experimental data, and the average error was about $3.7 \%$. Subsequently, the process was simulated, and the effects of feed flowrate and temperature, and the effect of tube wall temperature on the process were investigated numerically. It was observed that the increase in feed temperature, additional steam in the feed, and increase in tube wall temperature had the same effects and led to methane conversion increase. On the other hand, increasing the feed flowrate caused the methane conversion to decrease. The decision variables were optimised using genetic algorithm for the maximum hydrogen production and the minimum methane that could be valuable for the industrial processes. Further studies are needed on elaborating the process optimisation by focusing more on the cost evaluation, as well as on optimisation of steam methane reformer for other purposes like electricity production.

\section{ACKNOWLEDGMENT}

Hereby, we would like to extend our gratitude to Bandar Abbas Refinery Complex Co. in Iran for their financial support. Mr. Mohammad Jafar Mousavi is also appreciatively acknowledged for technical support and collaboration on data gathering.

\section{Nomenclature}

Symbols

$C_{p} \quad-$ specific heat, $\mathrm{J} \mathrm{mol}^{-1} \mathrm{~K}^{-1}$

$d_{i} \quad-\quad$ internal tube diameter, $\mathrm{m}$

$D_{p} \quad$ - equivalent catalyst pellet diameter, $\mathrm{m}$

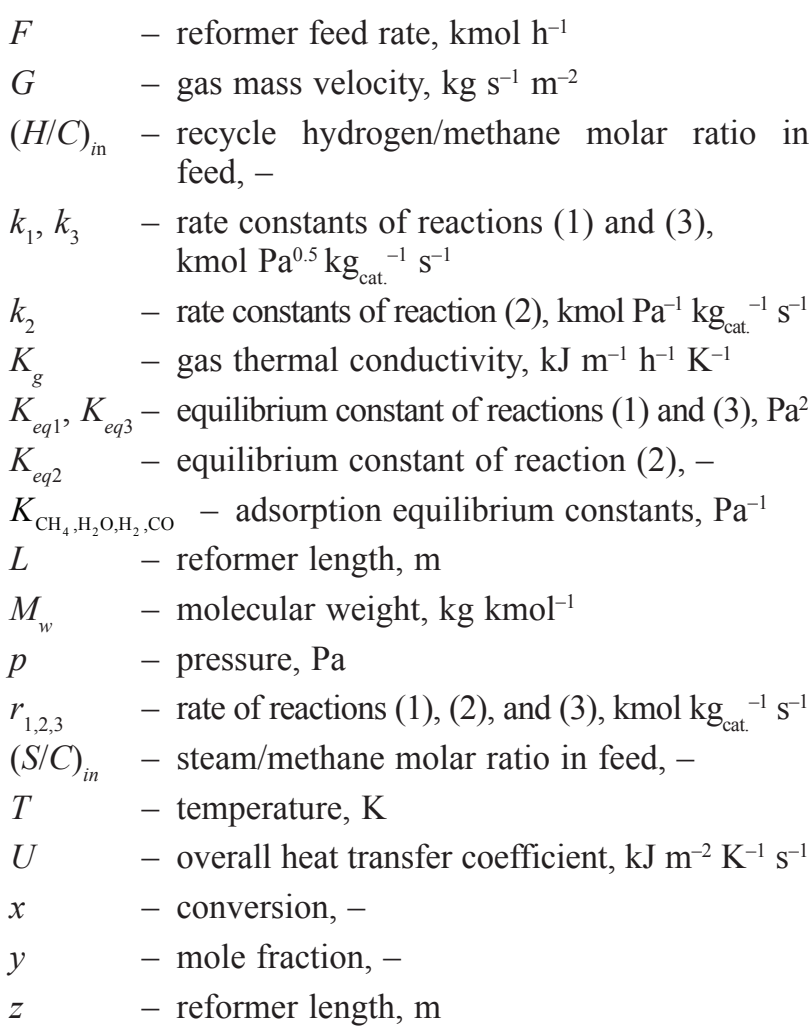

\section{Greek letters}

$\Delta H_{\mathrm{r}}$ - reaction enthalpy, $\mathrm{kJ} \mathrm{kmol}^{-1}$

$\varepsilon_{b} \quad$ - catalyst bed void fraction, -

$\eta_{1,23}$ - effectiveness factor for reactions (1), (2), and (3), -

$\mu \quad-$ viscosity, $\mathrm{kg} \mathrm{m}^{-1} \mathrm{~s}^{-1}$

$\rho \quad-$ density, $\mathrm{kg} \mathrm{m}^{-3}$

$\phi \quad-$ Thiele modules

\section{Indices}

b - catalyst bulk

eq. - equilibrium

$g \quad-$ gas

in. - reformer input

$k \quad-k$-th component

$m$ - mixtures

w - wall

\section{References}

1. Li, L., Tang, D., Song, Y., Jiang, B., Zhang, Q., Hydrogen production from ethanol steam reforming on $\mathrm{Ni}-\mathrm{Ce} / \mathrm{MMT}$ catalysts, Energy 149 (2018) 937. doi: https://doi.org/10.1016/j.energy.2018.02.116

2. Taji, M., Farsi, M., Keshavarz, P., Real time optimization of steam reforming of methane in an industrial hydrogen plant, Int. J. Hydrog. Energy 43 (2018) 13110. doi: https://doi.org/10.1016/j.ijhydene.2018.05.094 
3. De Deken, J. C., Devos, E. F., Froment, G. F. Steam Reforming of Natural Gas: Intrinsic Kinetics, Diffusional Influences, and Reactor Design, in Wei, J. and Georgakis, C. (Eds.), Chemical Reaction Engineering, American Chemical Society, Boston, 1982, 181. doi: https://doi.org/10.1021/bk-1982-0196.ch016

4. Nieva, M. A., Villaverde, M. M., Monzón Bescós, A., Garetto, T. F., Marchi, A. J., Steam-methane reforming at low temperature on nickel-based catalysts, Chem. Eng. J. 235 (2014) 158.

doi: https://doi.org/10.1016/j.cej.2013.09.030

5. Byrne, P. J., Gohr, E. J., Elizabeth, N. J., Haslam, R. T. Recent progress in hydrogenation of petroleum, Ind. Eng. Chem. 24 (1932) 1129. doi: https://doi.org/10.1021/ie50274a009

6. Rostrup-Nielsen, J., Steam reforming of hydrocarbons. A historical perspective, in Bao X. and Xu, Y. (Eds.), Studies in Surface Science and Catalysis, Elsevier, 2004, 121. doi: https://doi.org/10.1016/S0167-2991(04)80038-7

7. Potocnik, P., Natural Gas, IntechOpen, 2010. doi: https://doi.org/10.5772/240

8. Berman, A., Karn, R. K., Epstein, M., Kinetics of steam reforming of methane on $\mathrm{Ru} / \mathrm{Al}_{2} \mathrm{O}_{3}$ catalyst promoted with Mn oxides, App. Catal. A-Gen. 282 (2005) 73. doi: https://doi.org/10.1016/j.apcata.2004.12.003

9. Ford, A., Gillich, A., Mirzania, P., 28 - Sustainable Energy and Energy Efficient Technologies, in Letcher, T.M. (Eds.), Future Energy, Third Edition, Elsevier, 2020, p. 611. doi: https://doi.org/10.1016/B978-0-08-102886-5.00028-1

10. Van Hook, J. P., Methane-steam reforming, Catal. Rev. 21 (1980) 1. doi: https://doi.org/10.1080/03602458008068059

11. Meloni, E., Martino, M., Palma, V., A short review on Ni based catalysts and related engineering issues for methane steam reforming, Catalysts 10 (2020) 352. doi: https://doi.org/10.3390/catal10030352

12. Takahashi, A., Inagaki, R., Torimoto, M., Hisai, Y., Matsuda, T., Ma, Q., Gil Seo, J., Higo, T., Tsuneki, H., Ogo, S., Norby, T., Sekine, Y., Effects of metal cation doping in $\mathrm{CeO}_{2}$ support on catalytic methane steam reforming at low temperature in an electric field, RSC Adv. 10 (2020) 14487. doi: https://doi.org/10.1039/D0RA01721C

13. Watanabe, F., Kaburaki, I., Shimoda, N., Satokawa, S., Influence of nitrogen impurity for steam methane reforming over noble metal catalysts, Fuel Process. Technol. 152 (2016) 15. doi: https://doi.org/10.1016/j.fuproc.2016.06.003

14. Herce, C., Cortés, C., Stendardo, S., Computationally efficient CFD model for scale-up of bubbling fluidized bed reactors applied to sorption-enhanced steam methane reforming, Fuel Process. Technol. 167 (2017) 747. doi: https://doi.org/10.1016/j.fuproc.2017.07.003

15. Sinaei Nobandegani, M., Sardashti Birjandi, M. R., Darbandi, T., Khalilipour, M. M., Shahraki, F., Mohebbi-Kalhori, D., An industrial steam methane reformer optimization using response surface methodology, J. Nat. Gas Sci. Eng. 36 (2016) 540 doi: https://doi.org/10.1016/j.jngse.2016.10.031

16. Chen, J., Yan, L., Song, $W ., X u, D$., Methane steam reforming thermally coupled with catalytic combustion in catalytic microreactors for hydrogen production, Int. J. Hydrog. Energy 42 (2017) 664.

doi: https://doi.org/10.1016/j.ijhydene.2016.12.114

17. Pashchenko, D., Effect of the geometric dimensionality of computational domain on the results of CFD-modeling of steam methane reforming, Int. J. Hydrog. Energy 43 (2018) 8662 .

doi: https://doi.org/10.1016/j.ijhydene.2018.03.183
18. Singh, C. P. P., Saraf, D. N., Simulation of side fired steam-hydrocarbon reformers, Ind. Eng. Chem. Process. Des. Dev. 18 (1979) 1. doi: https://doi.org/10.1021/i260069a001

19. Alatiqi, I. M., Meziou, A. M., Gasmelseed, G. A., Modelling, simulation and sensitivity analysis of steam-methane reformers, Int. J. Hydrog. Energy 14 (1989) 241. doi: https://doi.org/10.1016/0360-3199(89)90061-X

20. Xu, J., Froment, G. F., Methane steam reforming, methanation and water-gas shift: I. Intrinsic kinetics, AIChE J. 35 (1989) 88 . doi: https://doi.org/10.1002/aic.690350109

21. Alhabdan, F. M., Abashar, M. A., Elnashaie, S. S. E., A flexible computer software package for industrial steam reformers and methanators based on rigorous heterogeneous mathematical models, Math. Comput. Model. 16 (1992) 77.

22. Nummedal, L., Røsjorde, A., Johannessen, E., Kjelstrup, S., Second law optimization of a tubular steam reformer, Chem. Eng. Process. 44 (2005) 429. doi: https://doi.org/10.1016/j.cep.2004.06.005

23. Riaz, A., Farsi, A., Zahedi, G., Manan, Z. A., Investigation of inert gas injection in steam reforming of methane: Energy, Int. J. Chem. Mol. Eng. 56 (2011) 648. doi: https://doi.org/10.5281/zenodo.1060100

24. Pantoleontos, G., Kikkinides, E. S., Georgiadis, M. C., A heterogeneous dynamic model for the simulation and optimisation of the steam methane reforming reactor, Int. J. Hydrog. Energy 37 (2012) 16346. doi: https://10.1016/j.ijhydene.2012.02.125

25. Sadooghi, P., Rauch, R., Pseudo heterogeneous modeling of catalytic methane steam reforming process in a fixed bed reactor, J. Nat. Gas Sci. Eng. 11 (2013) 46. doi: https://10.1016/j.jngse.2012.12.002

26. Shinde, V. M., Madras, G., Catalytic performance of highly dispersed $\mathrm{Ni} / \mathrm{TiO}_{2}$ for dry and steam reforming of methane, RSC Adv. 4 (2014) 4817. doi: https://doi.org/10.1039/C3RA45961F

27. Katoch, S., Chauhan, S. S., Kumar, V., A review on genetic algorithm: Past, present, and future, Multimed. Tools Appl. 80 (2021) 8091. doi: https://doi.org/10.1007/s11042-020-10139-6

28. Haghi, S. B., Salehi, G., Azad, M. T., Nichkoohi, A. L., 3D CFD modeling and optimization of a cylindrical porous bed reactor for hydrogen production using steam reforming of methane, Pet. Chem. 60 (2020) 1251. doi: https://doi.org/10.1134/S0965544120110109

29. Chen, Z., Po, F., Grace, J. R., Lim, C. J., Elnashaie, S., Mahecha-Botero, A., Rakib, M., Shirasaki, Y., Yasuda, I., Sorbent-enhanced/membrane-assisted steam-methane reforming, Chem. Eng. Sci. 63 (2008) 170. doi: https://doi.org/10.1016/j.ces.2007.09.031

30. Rydén, M., Lyngfelt, A., Using steam reforming to produce hydrogen with carbon dioxide capture by chemical-looping combustion, Int. J. Hydrog. Energy 31 (2006) 1271. doi: https://doi.org/10.1016/j.ijhydene.2005.12.003

31. Oh, P. P., Rangaiah, G. P., Ray, A. K., Simulation and multiobjective optimization of an industrial hydrogen plant based on refinery off-gas, Ind. Eng. Chem. Res. 41 (2002) 2248 .

doi: https://doi.org/10.1021/ie010277n

32. Xiu, G.-h., Li, P., Rodrigues, A. E., Sorption-enhanced reaction process with reactive regeneration, Chem. Eng. Sci. 57 (2002) 3893. doi: https://doi.org/10.1016/S0009-2509(02)00245-2 
33. Elnashaie, S. S. E. H., Elshishini, S. S., Modelling, Simulation and Optimization of Industrial Fixed Bed Catalytic Reactors, Gordon and Breach Sience Publlishers, Amsterdam, 1993, 426.

34. Al-Dhfeery, A. A., Jassem, A. A., Modeling and simulation of an industrial secondary reformer reactor in the fertilizer plants, Int. J. Ind. Chem. 3 (2012) 14 doi: https://doi.org/10.1186/2228-5547-3-14

35. Richardson, J. F., Peacock, D. G., Coulson \& Richardson's Chemical Engineering, Butterworth-Heinemann, Oxford, 1994, 116

36. $Y u, Y$. H., Simulation of secondary reformer in industrial ammonia plant, Chem. Eng. Technol. 25 (2002) 307. doi: https://doi.org/10.1002/1521-4125(200203)25:3<307::AID-CEAT307>3.0.CO;2-C

37. Bird, R. B., Stewart, W. E., Lightfoot, E. N., Transport phenomena, Wiley, New York, 2002, 527 and 866.

38. Nandasana, A. D., Ray, A. K., Gupta, S. K., Dynamic model of an industrial steam reformer and its use for multiobjective optimization, Ind. Eng. Chem. Res. 42 (2003) 4028. doi: https://doi.org/10.1021/ie0209576

39. Levenspiel, O., Chemical Reaction Engineering, Wiley, New York, 1999, 208.

40. Asano, K., Mass Transfer: From Fundamentals to Modern Industrial Applications, Wiley, Weinheim, 2007, 265.

41. Chung, T. H., Ajlan, M., Lee, L. L., Starling, K. E., Generalized multiparameter correlation for nonpolar and polar fluid transport properties, Ind. Eng. Chem. Res. 27 (1988) 671. doi: https://doi.org/10.1021/ie00076a024

42. Srinivas, N., Deb, K., Multiobjective optimization using nondominated sorting in genetic algorithms, Evol. Comp. 2 (1994) 221

doi: https://doi.org/10.1162/evco.1994.2.3.221
43. Pashchenko, D., Makarov, I., Carbon deposition in steam methane reforming over a Ni-based catalyst: Experimental and thermodynamic analysis, Energy 222 (2021) 119993. doi: https://doi.org/10.1016/j.energy.2021.119993

44. Pashchenko, D., Thermodynamic equilibrium analysis of steam methane reforming based on a conjugate solution of material balance and law action mass equations with the detailed energy balance, Int. J. Energy Res. 44 (2020) 438. doi: https://doi.org/10.1002/er.4943

45. Wang, M., Wang, X., Deng, C., Liu, B., Sun, C., Chen, G., Process Modeling and Energy Efficiency Analysis of Natural Gas Hydrate Production by $\mathrm{CH}_{4}-\mathrm{CO}_{2} / \mathrm{H}_{2}$ Replacement Coupling Steam Methane Reforming, Proceedings of the $9^{\text {th }}$ International Conference on Foundations of Computer-Aided Process Design, 2019. doi: https://doi.org/10.1016/B978-0-12-818597-1.50022-9

46. Chibane, L., Djellouli, B., Methane steam reforming reaction behaviour in a packed bed membrane reactor, Int. J. Chem. Eng. Appl. 2 (2011) 147. doi: https://doi.org/10.7763/IJCEA.2011.V2.93

47. Spivey, J. J., Deactivation of Reforming Catalysts, in Shekhawat, D., Spivey, J. J. and Berry, D. (Eds.), Fuel Cells: Technologies for Fuel Processing, Elsevie $\rightarrow$ r, Boston, 2011, 285 doi: https:/doi.org/10.1016/B978-0-444-53563-4.10010-0

48. Madon, R. H., Fawzi, M., Sarwani, K. I., Osman, S. A., Razali, M. A., Mohammad, A. W., Effect of steam to carbon ratio $(\mathrm{S}: \mathrm{C})$ on steam methane reforming's yield over coated nickel aluminide $\left(\mathrm{Ni}_{3} \mathrm{Al}\right)$ catalyst in micro reactor, J. Kejuruteraan 32 (2020) 657

doi: https://doi.org/10.17576/jkukm-2020-32(4)-14 